\title{
Article
}

Subscriber access provided by King Abdullah University of Science and Technology Library

\section{Creating Hierarchical Pores by Controlled Linker Thermolysis in Multivariate Metal-Organic Frameworks}

Liang Feng, Shuai Yuan, Liang-Liang Zhang, Kui Tan, Jia-Luo Li, Angelo

Kirchon, Ling-Mei Liu, Peng Zhang, Yu Han, Yves J. Chabal, and Hong-Cai Zhou

J. Am. Chem. Soc., Just Accepted Manuscript • DOI: 10.1021/jacs.7b12916 • Publication Date (Web): 18 Jan 2018

Downloaded from http://pubs.acs.org on January 23, 2018

\section{Just Accepted}

"Just Accepted" manuscripts have been peer-reviewed and accepted for publication. They are posted online prior to technical editing, formatting for publication and author proofing. The American Chemical Society provides "Just Accepted" as a free service to the research community to expedite the dissemination of scientific material as soon as possible after acceptance. "Just Accepted" manuscripts appear in full in PDF format accompanied by an HTML abstract. "Just Accepted" manuscripts have been fully peer reviewed, but should not be considered the official version of record. They are accessible to all readers and citable by the Digital Object Identifier (DOI®). "Just Accepted" is an optional service offered to authors. Therefore, the "Just Accepted" Web site may not include all articles that will be published in the journal. After a manuscript is technically edited and formatted, it will be removed from the "Just Accepted" Web site and published as an ASAP article. Note that technical editing may introduce minor changes to the manuscript text and/or graphics which could affect content, and all legal disclaimers and ethical guidelines that apply to the journal pertain. ACS cannot be held responsible for errors or consequences arising from the use of information contained in these "Just Accepted" manuscripts. 


\section{INTRODUCTION}

Metal-organic frameworks (MOFs) are a class of porous crystalline materials with great potential in gas storage, separation, catalysis and sensing. ${ }^{1}$ The pore environments of a MOF can be precisely tuned by controlling the linker connectivity and length, the type and number of functional groups on the linker, the metal node nuclearity and connectivity, the number of open coordination sites on each metal, and the overall topology of the MOF. ${ }^{2}$ However, most MOFs exhibit microporosity, which impedes the diffusion of large molecules. Their structural integrity is often compromised when they are exposed to moisture, aqueous solution or high temperature, which limits their utility in catalysis and other applications. ${ }^{3}$ Furthermore, when a microporous MOF is used to immobilize enzyme and other large-size catalysts, the active-site accessibility and catalytic activity will plummet because of pore blockage. ${ }^{4}$ Thus, sufficient pore size, appropriate stability and hierarchical porosity are three prerequisites for open frameworks designed for drug delivery, enzyme immobilization and catalysis involving large molecules.
Currently, two main approaches, direct or templated synthesis, have been developed to build hierarchically porous MOFs (HP-MOFs). PCN-222, PCN-333 and NU-10oo are HP-MOFs from direct synthesis. 5 Yet the number of such MOFs, whose pore size distribution is predetermined by the linker length and MOF topology, is limited. In the latter approach, templates are incorporated at random in the framework during the in situ MOF synthesis. ${ }^{6}$ Although the removal of template molecules may create mesopores inside the MOF, it often triggers partial or even total collapse of the framework, leading to reduced crystallinity, low porosity, and poor stability. An unconventional alternative is to judiciously utilize labile chemical bonds or linkers susceptible to cleavage for the construction of porous materials, which should play an essential role in making HP-MOFs that could not be obtained otherwise. ${ }^{7,8}$

This pore engineering strategy based on labile chemical bonds has been explored extensively recently, leading to MOF construction strategies such as linker installation, linker labilization, solvent-assisted ligand incorporation and modulator removal in Zr-MOFs (Figure S1). ${ }^{9}$ Linker installation $^{9 \mathrm{a}, \mathrm{g}^{\mathrm{b}}}$ and solvent-assisted ligand incorporation ${ }^{9 \mathrm{c}}$ 
both utilize acid-base chemistry between the hydroxyl groups on the coordinatively-unsaturated $\mathrm{Zr}_{6} \mathrm{O}_{4}(\mathrm{OH})_{8}\left(\mathrm{H}_{2} \mathrm{O}\right)_{4}$ clusters and linear linkers or terminal ligands. The terminal $-\mathrm{OH} / \mathrm{H}_{2} \mathrm{O}$ on these positions are further replaced by carboxylates in the solution postsynthetically. Linker labilization ${ }^{\mathrm{e}}$ and modulator removal9d are two reverse processes to linker installation and solvent-assisted ligand incorporation. In modulator removal, a MOF is initially constructed with coordinatively-saturated clusters and modulator as terminal ligands; the terminal ligands are subsequently removed by activation under vacuum at high temperatures. This method leads to the formation of a more open framework with a large number of open coordination sites, which could act as catalytic centers in Lewis acid catalyzed reactions. However, the pore size of this resulting microporous framework increases only slightly, which is still unsuitable for applications involving large molecules. In contrast, linker labilization is a powerful tool to produce hierarchically porous structures with precisely controllable pore size distributions. A mixed-linker MOF is constructed with a "pro-labile" linker, which represents a non-labile linker that can be converted to a labile one in a single step. The defects are created subsequently by splitting the "pro-labile" linker into two labile monocarboxylates under acidic conditions. Yet, several concerns still remain in linker labilization. First, the relatively long ligand used in PCN-16o would lead to an overall compromised stability. ${ }^{10}$ Secondly, linker labilization has only been successful in a few particular examples, which highly restricts its application scope. This is because the "pro-labile" linker used in the framework is intrinsically reactive, and therefore decomposes under common synthetic conditions. This in turn makes it challenging to incorporate the "pro-labile" linkers into the framework. Therefore, it is urgent to find highly stable prototypical MOFs with relatively stable substitutes for previously reported imine-based linker, which can still undergo linker decomposition post-synthetically, in order to prepare ultrastable HP-MOFs with large pore sizes.

Herein, we introduce a powerful and general strategy, called linker thermolysis, to create mesopores in a series of microporous MOFs controllably. Initially, a multivariate
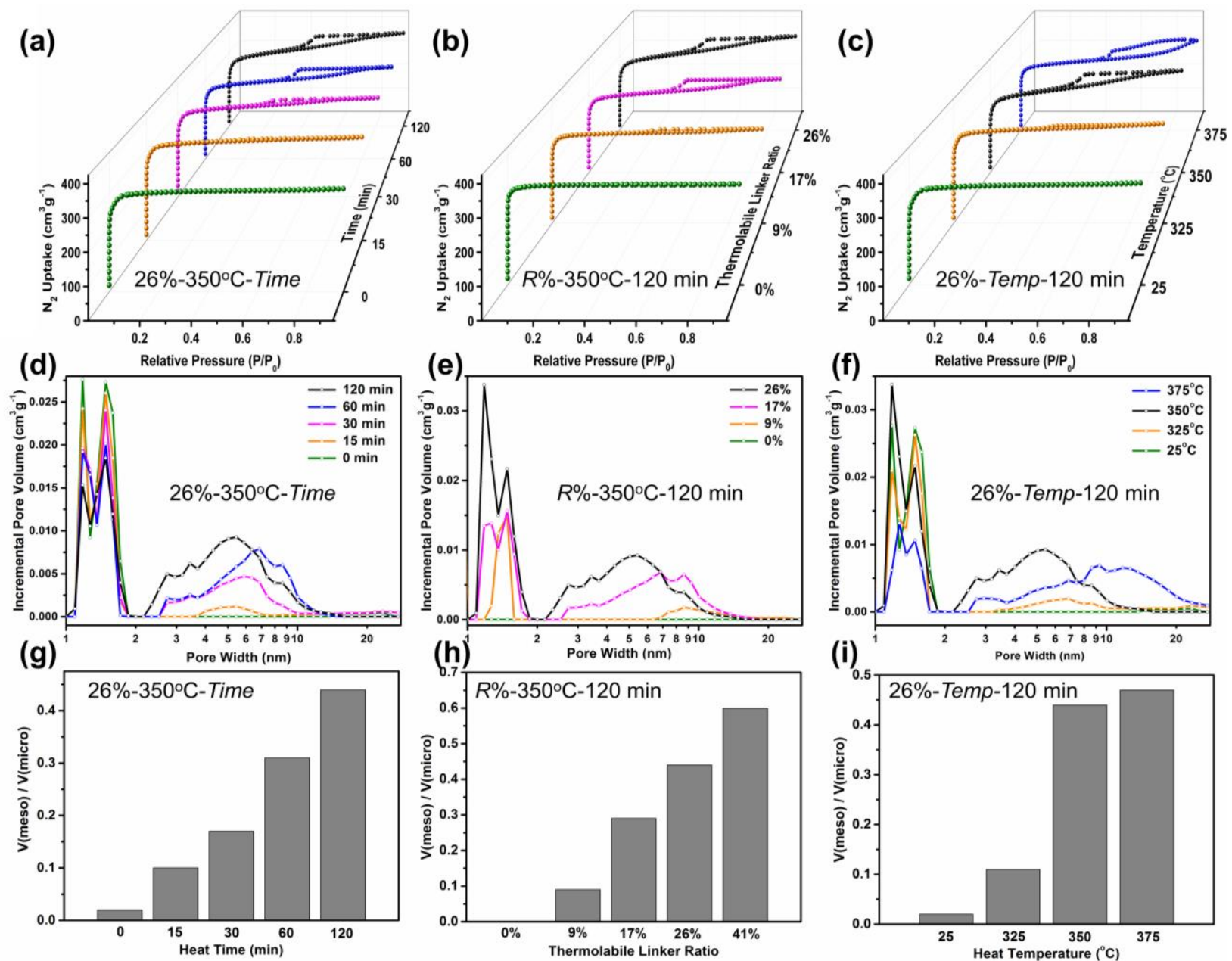

Figure 1. Controlled formation of mesopores inside MTV-UiO-66. $\mathrm{N}_{2}$ sorption isotherms, pore size distributions and

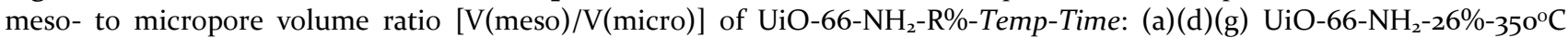
heated with various time periods; (b)(e)(h) UiO-66- $\mathrm{NH}_{2}-\mathrm{R} \%-350^{\circ} \mathrm{C}-120$ min containing $\mathrm{R} \% \mathrm{BDC}^{-\mathrm{NH}_{2}}$; (c)(f)(i) UiO-66-NH 26\%-120 min heated under different temperatures. The pore size distributions of UiO-66-NH $\mathrm{N}_{2}$ - $\mathrm{R}$-Temp-Time samples were calculated from the $\mathrm{N}_{2}$ adsorption isotherms using a density functional theory (DFT) model. 
MOF (MTV-MOF) is built from ordinary and thermal-sensitive (thermolabile) linkers. The thermolabile linker can then be selectively cleaved in the framework through a decarboxylation process, by carefully controlling the decomposition temperature. Hierarchical pores are created while the crystallinity and chemical stability remain after linker thermolysis. It is analogous to the modulator removal process, a thermal method to remove terminal ligands instead of bridging ones as in linker thermolysis. There exists a stark contrast between the stability of common and thermolabile linkers due to their distinct functional groups, which leads to selective thermolysis. ${ }^{11}$ Not only does linker thermolysis allow for the generation of tunable hierarchically porous structures in a series of ultrastable MOFs with various clusters and functional groups, but it can also produce ultrasmall metal oxide (MO) nanoparticles immobilized in the framework. This resulting composite material, denoted as MO@HP-MOF, offers new opportunities for large molecule adsorption and catalysis.

\section{RESULTS AND DISCUSSION}

Creating hierarchical pores in MTV-MOFs. UiO-66, one of the most studied MOFs, was firstly introduced as an example to illustrate our strategy because of its excellent stability and strong tolerance towards defects. ${ }^{12}$ The linker, 2-Amino-1,4-benzenedicarboxylate $\left(\mathrm{BDC}-\mathrm{NH}_{2}\right)$, was applied as the thermolabile linker, which can be easily removed under relatively low temperature $\left(300^{\circ} \mathrm{C}\right)$ through thermal decomposition. In contrast, UiO-66 with BDC as linker shows high thermal stability, starting decomposition at nearly $480^{\circ} \mathrm{C}$ (Fig. $\left.\mathrm{S}_{4}\right)$. The remarkable thermal stability differences provide an excellent platform to study the aforementioned selective linker thermolysis strategy. MTV-UiO-66- $\mathrm{NH}_{2}-\mathrm{R} \%$, where $\mathrm{R} \%$ stands for the percentage of the thermolabile linker determined by ${ }^{1} \mathrm{H}-\mathrm{NMR}(\mathrm{Nu}-$ clear Magnetic Resonance, Table S1), were synthesized with good crystallinity as indicated from PXRD (Powder XRay Diffraction) patterns and TEM (Transmission Electron Microscope) images. $\mathrm{N}_{2}$ sorption isotherms indicated that MTV-UiO-66 samples were microporous as expected with an extra reo-type ${ }^{13}$ micropore diameter of $\sim 15 \AA$ due to missing-cluster defects, which is very common in $\mathrm{Zr}$ - and Hf-MOFs.

Thermal stability of UiO-66- $\mathrm{NH}_{2}-\mathrm{R} \%$ was accessed by thermogravimetric analysis (TGA) (Fig. S4). TGA plots indicate thermal stability of $\mathrm{UiO}-66-\mathrm{NH}_{2}-\mathrm{R} \%$ decreases with increasing $\mathrm{R} \%$. UiO-66 samples with $\mathrm{BDC}-\mathrm{NH}_{2}$ ratios varying from o to $41 \%$ were prepared and treated with various temperatures for certain periods of time. The resulting materials are denoted as UiO-66- $\mathrm{NH}_{2}-\mathrm{R} \%$-Temp-Time, where Temp represents the thermal treatment temperature and Time represents the thermal treatment time. PXRD measurements showed that the MOF materials after thermolysis possessed the same diffraction patterns as the parent UiO-66 MOF (Fig. S5). The crystal morphology was not affected by the relatively mild heating process as indicated by the TEM images of the respective particles (Fig. S13-14).
The $\mathrm{N}_{2}$ sorption isotherms at $77 \mathrm{~K}$ demonstrated the formation of HP-MOF materials, which possess both microand mesopores (Fig. 1, Fig. S8).

In general, the porosities and pore sizes of these MOFs could be easily tuned through varying the thermolabile linker ratio, temperature and heat time. When sample UiO-66- $\mathrm{NH}_{2}-26 \%-350^{\circ} \mathrm{C}$ was held under the temperature for different periods of $15 \mathrm{~min}, 30 \mathrm{~min}$, $60 \mathrm{~min}$, and $120 \mathrm{~min}$, the porosities and $\mathrm{N}_{2}$ uptakes increased as heating time became longer. Noticeable mesopores with an average diameter of $5.5 \mathrm{~nm}$ emerged after thermal treatment. The ratio of meso- to micropore volume increased proportionally with the elongated time period as indicated by $\mathrm{N}_{2}$ uptake and pore size distribution. The effects of thermolysis temperature and thermolabile linker ratio on the porosity and pore size distribution were also studied. When UiO-66$\mathrm{NH}_{2}-26 \%-120$ min was set as the basis, the overall porosity and $\mathrm{N}_{2}$ uptake increased as the thermolysis temperature elevated. A pronounced hysteresis loop, corresponding to mesopores with average diameter of $5.5 \mathrm{~nm}$, arose when temperature reached $325^{\circ} \mathrm{C}$. Further temperature increase to $350^{\circ} \mathrm{C}$ led to the augmentation of the proportion of 5.5 $\mathrm{nm}$ mesopores, however, the average pore size remained almost unchanged. When the temperature was raised to $375^{\circ} \mathrm{C}, \mathrm{BDC}-\mathrm{NH}_{2}$ decomposed completely, which caused the porosity expansion to $13 \mathrm{~nm}$. In addition, when the thermolabile linker ratio increased, so did the porosity and $\mathrm{N}_{2}$ uptake as expected. Further raise of the ratio of the thermolabile linker and the temperature of thermolysis led to the compromise of the framework integrity as indicated by the decreased $\mathrm{N}_{2}$ uptake (Fig. S9-10).

The hierarchical porosity is also corroborated by TEM images (Fig. 2, Fig. S13-14). After linker thermolysis, the HP-UiO-66 MOFs display a sponge-like morphology with defects randomly arranged throughout each particle. The crystallinity of all samples after thermal treatment remains intact as indicated by PXRD, although slightly broader PXRD peaks were observed for frameworks with a larger

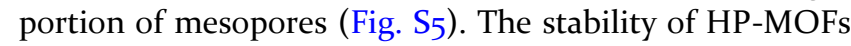
toward aqueous solution has also been investigated. Although a large number of defects have been created inside the framework, HP-UiO-66 retained the chemical stability of the pristine UiO-66 (Fig. 2d). The ultrastable nature of $\mathrm{HP}-\mathrm{UiO}-66$ is encouraging as MOF with hierarchical pores and high stability should be ideal for practical applications. Additionally, nanoparticles with ultrasmall sizes $(1-3 \mathrm{~nm})$ were generated from the linker thermolysis process. TEM images showed that the ultrasmall $\mathrm{ZrO}_{2}$ nanoparticles are well-dispersed in the framework by the clear lattice fringes with a lattice spacing of $0.295 \mathrm{~nm}$, corresponding to a stack of the [101] planes of the tetragonal $\mathrm{ZrO}_{2}$ lattice (Fig. 2f).14 The composite MO@HP-MOFs were expected to be an active catalyst for three reasons: (a) the ultrasmall nanoparticles are highly dispersed throughout the HP-UiO-66 MOFs; (b) the resulting framework will provide sufficient space to host the catalytic active sites; (c) the hierarchical porous structure would enable reactions involving large molecules while facilitating the diffusion of previously forbidden reactants, reaction intermediates, and products. 
(a)

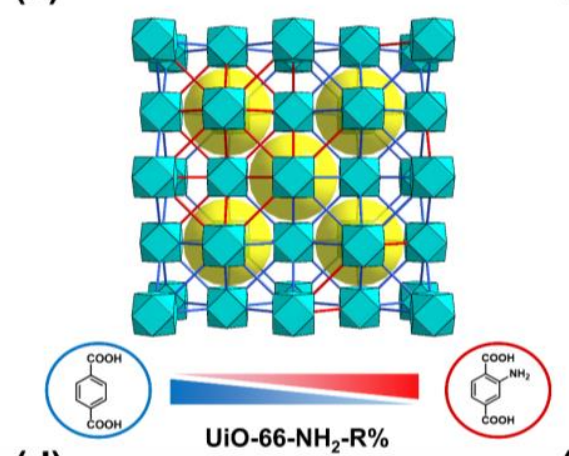

(d)

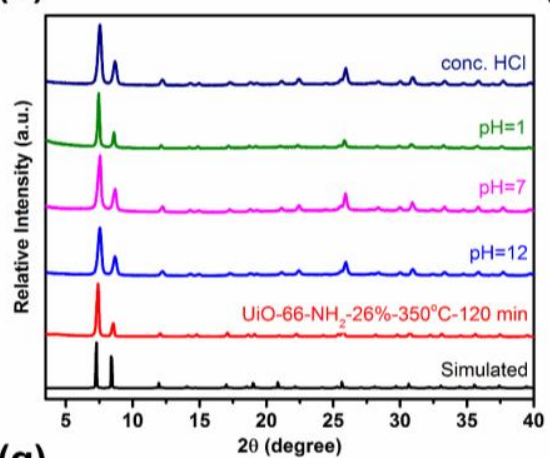

(g)

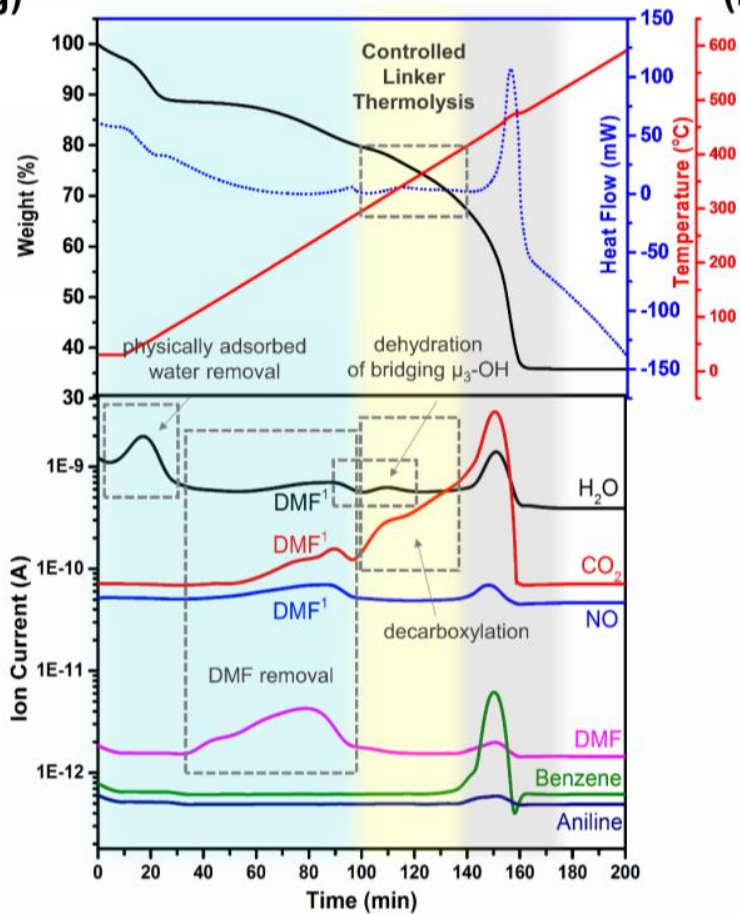

(b)

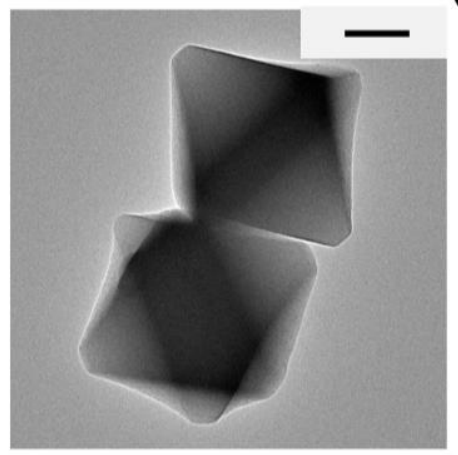

(e)

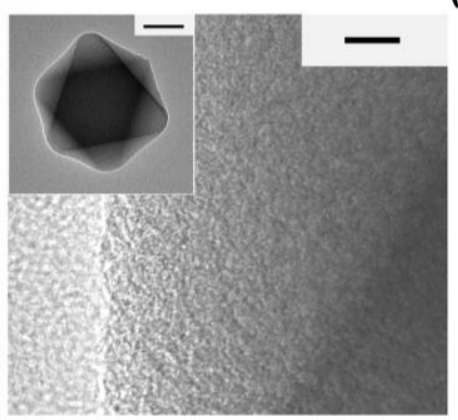

(f)

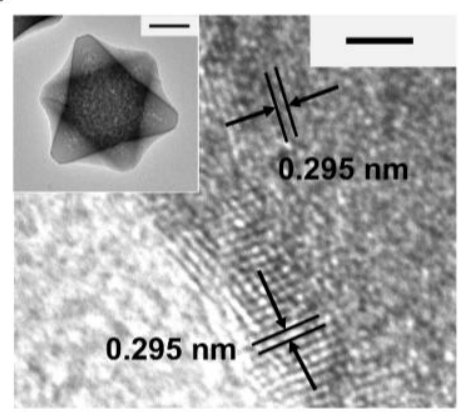

(c)

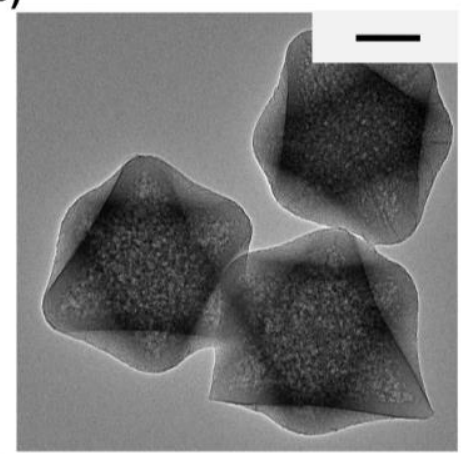

(h)

Figure 2. Structural characterizations of MTV-UiO-66/HP-UiO-66 and mechanistic studies on linker thermolysis. (a) Structure of MTV-UiO-66- $\mathrm{NH}_{2}-\mathrm{R} \%$; (b)(e) TEM images of UiO-66- $\mathrm{NH}_{2}-26 \%$ single crystals before thermal treatment; (c)(f) TEM images of UiO-66- $\mathrm{NH}_{2}-26 \%$ single crystals after thermolysis; well dispersed ultrasmall particles of $\mathrm{ZrO}_{2}$ with $0.295 \mathrm{~nm}$ interplanar spacing $\left(\mathrm{d}_{101}\right)$ could be found in (f). Scale bar is $100 \mathrm{~nm}$ in $(\mathrm{b})(\mathrm{c})$ and insert of $(\mathrm{e})(\mathrm{f}), 5 \mathrm{~nm}$ in (e), and $2 \mathrm{~nm}$ in (f). (d) PXRD patterns showing chemical stability of HP-UiO-66; (g) Linker thermolysis of UiO-66- $\mathrm{NH}_{2}-26 \%$ investigated by TGAMS. Color scheme of MS signals: black-water $(\mathrm{m} / \mathrm{z}=18)$, blue- $\mathrm{NO}(\mathrm{m} / \mathrm{z}=30)$, red- $\mathrm{CO}_{2}(\mathrm{~m} / \mathrm{z}=44)$, pink- DMF (Dimethylformamide, $\mathrm{m} / \mathrm{z}=42)$, green-benzene $(\mathrm{m} / \mathrm{z}=78)$, and indigo-aniline $(\mathrm{m} / \mathrm{z}=93)$ recorded during decomposition/oxidation of MOFs. ${ }^{1}$ Note that DMF has multiple MS signals at $\mathrm{m} / \mathrm{z} 18$, 30 and 44. (h) IR absorption spectra: the bottom panel shows the full MOF IR absorption spectrum of $\mathrm{UiO}-66-\mathrm{NH}_{2}-26 \%$ at $100^{\circ} \mathrm{C}$, referenced to $\mathrm{KBr}$ pellet without the MOF powder; the top panel shows the differential spectra as a function of annealing temperature under $\mathrm{N}_{2}$ flow $(5 \mathrm{mn}$ at each temperature, then as noted), each referenced to the spectrum collected after the previous annealing treatment: the $150^{\circ} \mathrm{C}$ spectrum is referenced to the $100^{\circ} \mathrm{C}$ spectrum and so forth. 
Mechanistic study of hierarchical structure formation. The decarboxylation mechanism of linker thermolysis was elucidated through many in situ and ex situ techniques. Combined TGA/MS studies were performed in air to determine the products of linker thermolysis. The TGA plots and corresponding MS signals under two conditions were summarized (Fig. 2g, Fig. S15): (a) increasing temperature from $30^{\circ} \mathrm{C}$ to $600^{\circ} \mathrm{C}$ and (b) holding at a constant temperature of $350^{\circ} \mathrm{C}$. As indicated in Fig. $2 \mathrm{~g}$, a small amount of water and DMF solvent trapped inside the pores or coordinated on $\mathrm{Zr}_{6}$ cluster firstly came out before temperature reached $300^{\circ} \mathrm{C}$. Between $300^{\circ} \mathrm{C}$ and $400^{\circ} \mathrm{C}$ (controlled linker thermolysis range), the amount of $\mathrm{CO}_{2}$ dramatically increased while no other signal was detected, which clearly indicated a decarboxylation process before the collapse of the framework. When temperature reached $400^{\circ} \mathrm{C}$, a sharp peak with MS signal $\mathrm{m} / \mathrm{z}=78$ appeared, corresponding to the cracking residue of the MOF linker. Additionally, to investigate the formation of mesopores in Fig. Id, UiO-66- $\mathrm{NH}_{2}-26 \%$ was held at $350^{\circ} \mathrm{C}$ and the gaseous products were analyzed with TGA/MS. Only the signal of
$\mathrm{CO}_{2}$ could be detected after the removal of solvents, which confirmed the decarboxylation process of $\mathrm{BDC}-\mathrm{NH}_{2}$ in the framework.

In situ infrared (IR) spectroscopy and ex situ X-ray photoelectron spectroscopy (XPS) were used to monitor the decarboxylation process of the sample upon thermal treatment. The losses (negative features) in the differential IR absorption spectra before $300^{\circ} \mathrm{C}$ anneal (Fig. $2 \mathrm{~h}$ ) are associated with solvent molecules including $\mathrm{H}_{2} \mathrm{O}[\mathrm{v}(\mathrm{OH})]$ and DMF $\left[v\left(-\mathrm{CH}_{3}\right)\right.$ and $\left.v(\mathrm{C}=\mathrm{O})\right]$. The process starts with dehydration of bridging $\mu_{3}-\mathrm{OH}$ of $\mathrm{Zr}_{6} \mathrm{O}_{4}(\mathrm{OH})_{4}$ (loss of the 3676 $\mathrm{cm}^{-1}$ mode above $250^{\circ} \mathrm{C}$ ) and proceeds with a transition to a $\mathrm{Zr}_{6} \mathrm{O}_{6}$ cluster, as evidenced by a slight blue shift of the symmetric and asymmetric stretching bands ${ }^{15}$ of the $\mathrm{COO}^{-}$ group bound to $\mathrm{Zr}$ metal center. Above $300^{\circ} \mathrm{C}$, there is a gradual loss of carboxylate bands $\left(1582,1428,1393 \mathrm{~cm}^{-1}\right)$, particularly at $350^{\circ} \mathrm{C}$ over the time observed, which was consistent with TGA-MS results. Ex situ XPS measurements, performed on UiO-66- $\mathrm{NH}_{2}-41 \%$, after thermal treatment of sample at $350^{\circ} \mathrm{C}$ for $\sim 5$ min and $3.5 \mathrm{~h}$ (Fig. S16), clearly show a decrease of the $\mathrm{COO}^{-} / \mathrm{Zr}$ ratio from $\sim 41 \%$ to

(a)

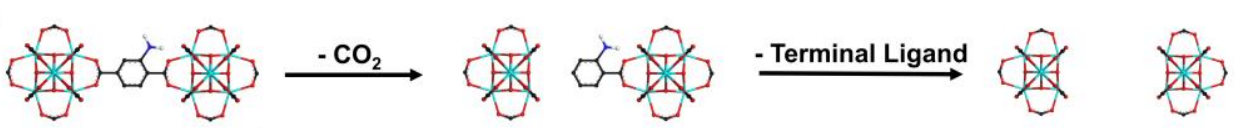

(b)

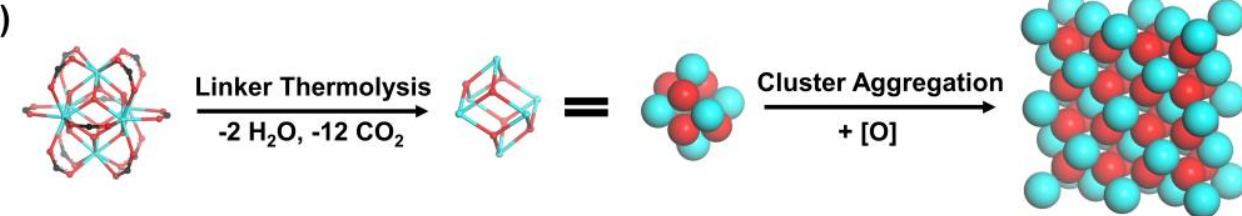

$\mathrm{Zr}_{6} \mathrm{O}_{4}(\mathrm{OH})_{4}\left(\mathrm{CO}_{2}\right)_{12}$ Cluster Distorted $\mathrm{Zr}_{6} \mathrm{O}_{6}$ Cluster Ultrasmall Metal Oxide

(c)

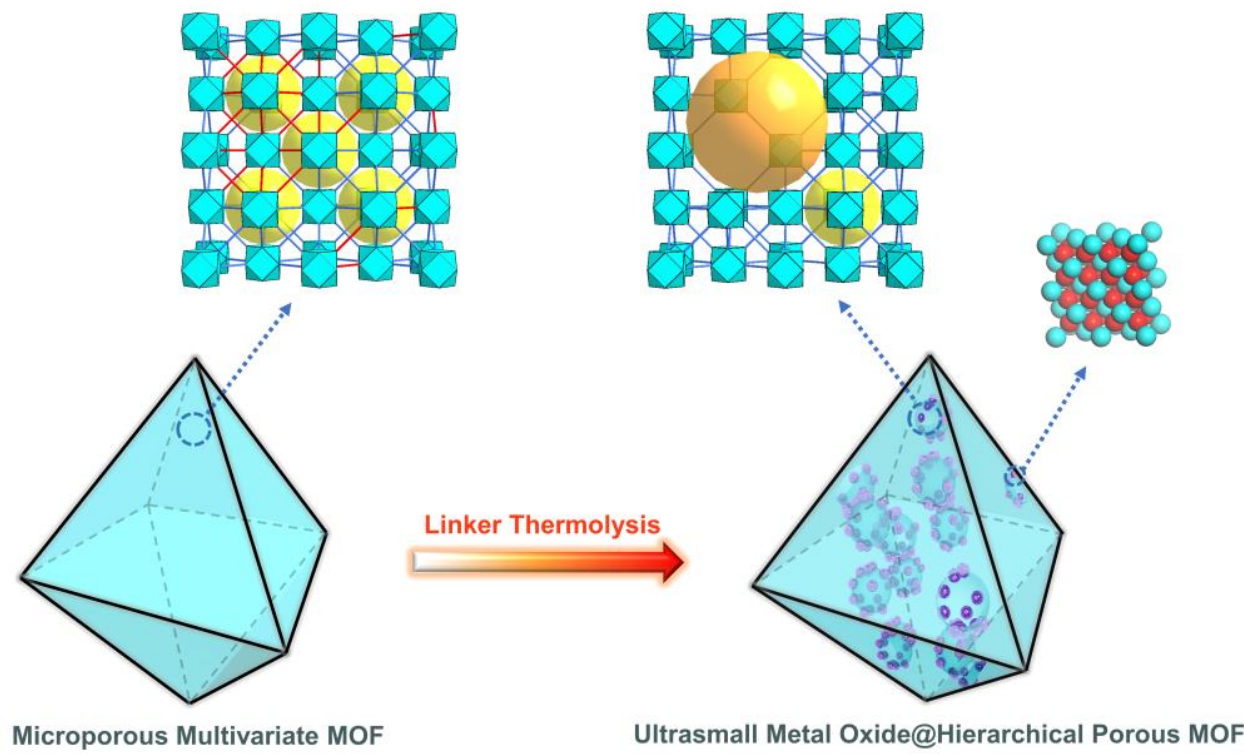

Figure 3. Mechanism of hierarchically porous structure formation. (a) The amino functionalized linker tends to undergo a decarboxylation process under relatively low temperature, and the resulting terminal ligand could be further removed through thermal or chemical treatments. (b) $\mathrm{Zr}_{6} \mathrm{O}_{4}(\mathrm{OH})_{4}\left(\mathrm{CO}_{2}\right)_{12}$ clusters are transformed into decarboxylated $\mathrm{Zr}_{6} \mathrm{O}_{6}$ clusters after linker thermolysis, and they tend to aggregate with the assistance of oxygen species, forming ultrasmall MO nanoparticles eventually. (c) Overall, the microporous MTV-MOF, UiO-66- $\mathrm{NH}_{2}-\mathrm{R} \%$, is converted into ultrasmall MO@HP-MOFs composites through controlled linker thermolysis. 
$\sim 25 \%$ after linker thermolysis at $350^{\circ} \mathrm{C}$ for $3.5 \mathrm{~h}$, which directly supports the decarboxylation inside the framework. Besides decarboxylation, there are also losses between 3500 to $3300 \mathrm{~cm}^{-1}$ and at $1257 \mathrm{~cm}^{-1}$, associated with $\mathrm{v}\left(-\mathrm{NH}_{2}\right)$ and $v(\mathrm{C}-\mathrm{N})$ modes, respectively, at $350^{\circ} \mathrm{C} .{ }^{15}$ These observations indicate that the amino-functionalized linker is a thermolabile part of the framework. Finally, variable-temperature PXRD was also used to monitor the in situ transformation of MOF structure (Fig. S17-18). The dramatic decline of the diffraction intensity of the [111] planes began at nearly $300^{\circ} \mathrm{C}$, which can be attributed to a structure change caused by the decarboxylation process.

As described above, thermally susceptible linkers tend to go through a decarboxylation process at relatively low temperatures while the other parts of the frameworks remain intact, as vacancies are created after the removal of $\mathrm{CO}_{2}$. Unlike the creation of missing linker and cluster defects by linker labilization that takes place in solution, linker thermolysis goes through a cluster aggregation process (Fig. 3).

(a)

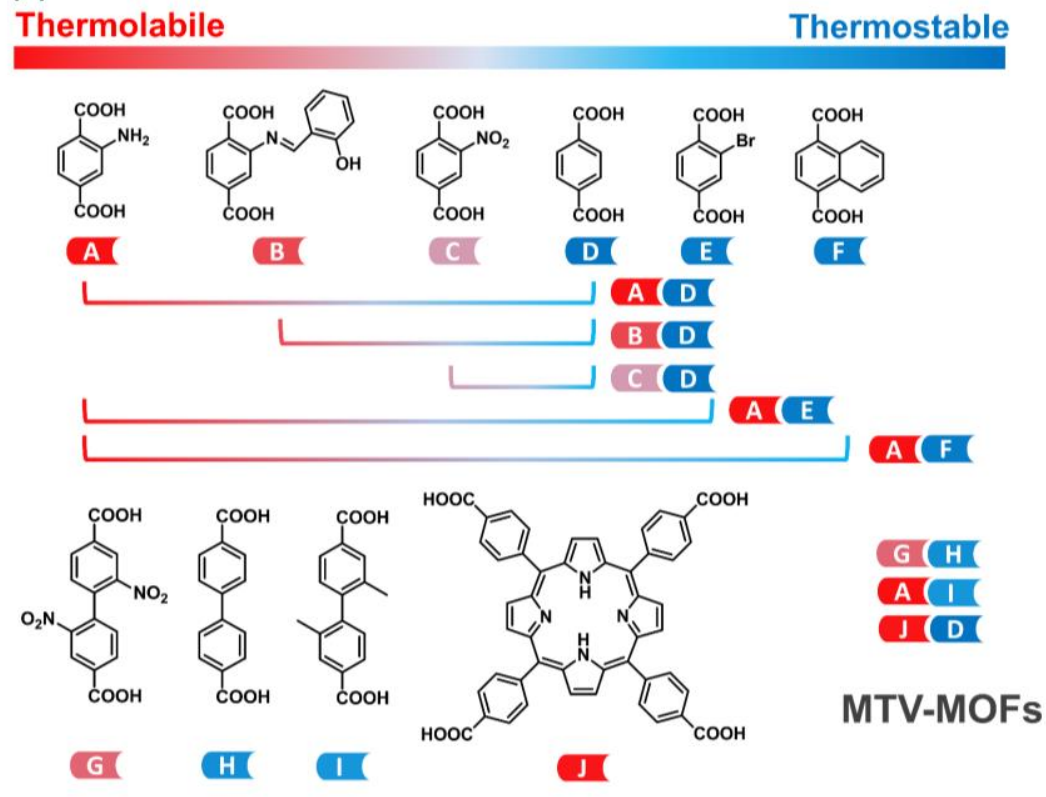

(b)

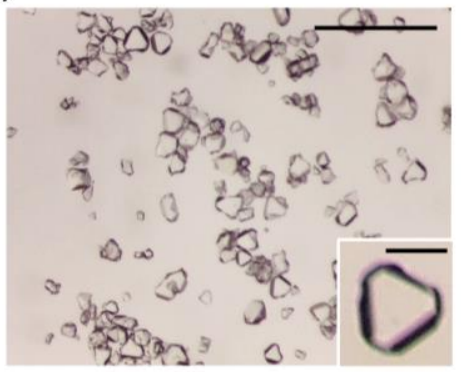

(d)

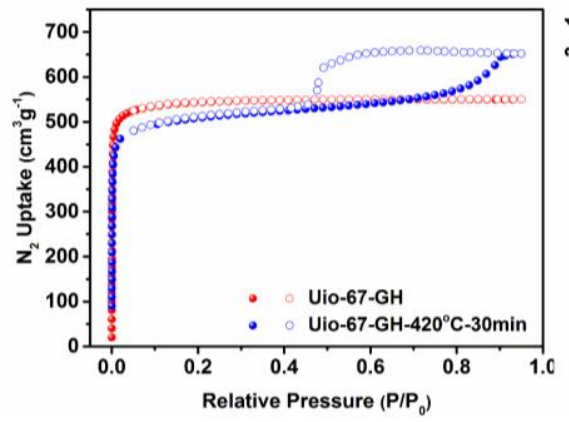

(c)

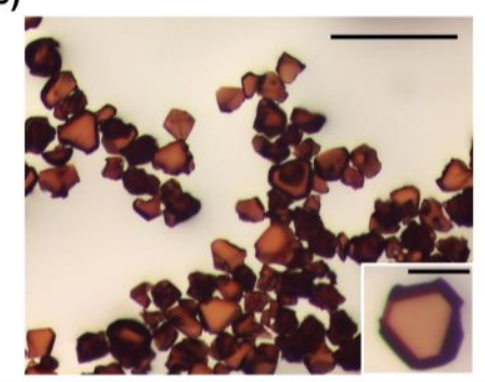

(e)

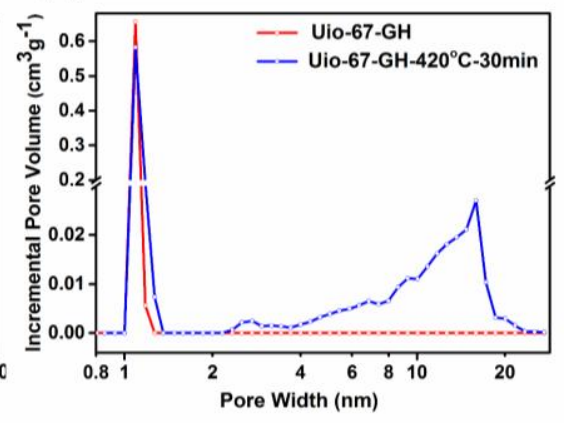

Figure 4. Versatility of controlled linker thermolysis. (a) Versality of linker thermolysis to construct HP-MOFs with various linkers A-J showing different thermal stability. Combination of relatively thermolabile and relatively thermostable linkers resulted in MTV-MOFs capable of controllable linker thermolysis. (b)(c) Images of UiO-67-GH crystals before and after linker thermolysis; (d)(e) $\mathrm{N}_{2}$ sorption isotherms and pore size distributions of UiO-67-GH before and after linker thermolysis. Scale bar is $500 \mu \mathrm{m}$ in (b)(c) and $100 \mu \mathrm{m}$ in (b)(c) insert figures. 
An interesting phenomenon in solid solution called Ostwald ripening may help explain the cluster aggregation. This occurs because the freshly formed decarboxylated $\mathrm{Zr}_{6} \mathrm{O}_{6}$ clusters ${ }^{16}$, with the assistance of oxygen species, tend to aggregate to form a "giant" $\mathrm{ZrO}_{2}$ cluster (ultra-small $\mathrm{ZrO}_{2}$ nanoparticle), which is a thermodynamically driven and spontaneous process (Fig. S27-28). The oxygen species presumably originate from the reduced oxygen during the oxidation of organic species. Based on the proposed mechanism, after thermolabile linkers undergo a decarboxylation process, the resulting fragments, terminal ligands, are still coordinated to the cluster. Two methods were then adopted to remove these terminal ligands in order to achieve even larger pore sizes: (1) thermal activation at high temperatures; (2) treatment with diluted acid solution. The pore sizes of HP-UiO-66 become notably larger after both treatments. (Fig. If, Fig. S23).

Versatility of linker thermolysis. To examine whether linker thermolysis could function as a general approach, we extended the strategy to other common linkers and other types of clusters for developing various highly stable HP-MOFs (Fig. 4). The influences of different functional groups on the thermal stabilities of the UiO-66 series were investigated. Herein we introduced six ligands, BDC and its derivatives (donated as A-F), and combined two linkers to form the corresponding sets of MTV-MOFs. Each MTVMOF possesses relative thermolabile and relative thermostable linkers. It is noteworthy that the TGA plots provided us direct information about the linker thermal stability. ${ }^{11}$ It is reasonable that the thermal stability of the corresponding frameworks increases in the order of $\mathrm{A} \approx \mathrm{B}<\mathrm{C}<\mathrm{D} \approx \mathrm{E}$ $\approx \mathrm{F}$ accompanied by decreasing capability of functional groups to withdraw electrons from the benzene ring. Guided by the weight loss information of MTV-MOFs from TGA curves, appropriate thermal treatment parameters including temperature and treatment time were chosen carefully to avoid the complete collapse of the framework. As expected, all sets of the UiO-66 series have been trans- formed from microporosity to hierarchical porosity without the loss of crystallinity or porosity (Fig. S29-35). By further extending the linker length, a single-crystalline MTVUiO-67-GH was synthesized through linker exchange. The pore size of UiO-67 was successfully tuned from 1.2 to 15 nm (Fig. 4d-e, Fig. S36-37) by controlled linker thermolysis. Optical images of UiO-67-GH crystals shown the wellmaintained single crystallinity after linker thermolysis (Fig. 4b-c), which was extremely difficult to achieve by conventional template-based methods.

To further verify the versatility of linker thermolysis, MTV-MOFs with different metal clusters, including MOF5(Zn), MIL-53(Fe), MIL-125(Ti), and UiO-66(Hf), were also tested. It is evident that the mesopores arose after the thermal treatment as indicated by gas sorption studies (Fig. $\mathrm{S}_{3} 8-42$, Table 1, Table $\mathrm{S}_{3}$ ). Note that postsynthesis annealing of single-linker $\mathrm{MOF}^{-}{ }_{5}$, companied by the formation of mesopores, has been previously reported by Gadipelli et al. ${ }^{17}$ However, controlled linker thermolysis in MTV-MOFs could achieve better tunability on both the amount and the distribution of mesopores by selectively removing thermolabile linkers, whose distribution could be tuned by controlling synthetic conditions.

Linker spatial distribution in MTV-MOFs and its relation to hierarchical structure formation. Realizing the arrangement of various functional groups within MTVMOFs was found to be critical for understanding the formation of hierarchically porous structures. Inspection of the possible models of linker apportionment would help us gain better insight into the mesoscale mechanism of nanodomain defect formation. Theoretically, when two linkers are mixed to form a MTV-MOF, the nondominant linker is considered to disperse in a matrix formed by the dominant linker, leading to domains with different sizes. Four scenarios of MTV-MOFs are categorized based on the size of domain: (a) Large Domain, (b) Small Domain, (c) Random and (d) Ordered model with no domain formed (Fig. 5). ${ }^{18}$ Linker thermolysis proceeds through the decarboxylation process, which enables us to selectively remove

Table 1. Porosity parameter of HP-MOFs created by linker thermolysis.

\begin{tabular}{cccc}
\hline HP-MOF & $\mathbf{S}_{\text {BET }^{\dagger}\left(\mathbf{c m}^{3} \mathbf{g}^{-1}\right)}$ & $\mathbf{D}_{\text {Meso }^{\ddagger}}(\mathbf{n m})$ & $\left.\left.\mathbf{V}^{(\mathbf{m e s o}}\right)^{\mathbf{\S} / \mathbf{V}(\mathbf{m i c r o})}\right)^{\|}$ \\
\hline HP-UiO-66-AD & 1022 & 9.8 & 0.83 \\
HP-UiO-66-BD & 1012 & 7.5 & 0.60 \\
HP-UiO-66-CD & 825 & 7.2 & 0.82 \\
HP-UiO-66-AE & 702 & 5.5 & 0.79 \\
HP-UiO-66-AF & 571 & 6.0 & 1.00 \\
HP-UiO-67-GH & 2185 & 14.8 & 0.66 \\
HP-MOF-5-AD (Zn) & 1736 & 9.8 & 0.55 \\
HP-MIL-125-AD (Ti) & 1038 & $2.0,21$ & 0.28 \\
HP-UiO-66-AD (Hf) & 734 & 5.5 & 0.42 \\
HP-MIL-53-AD (Fe) & 113 & 60 & 11.55 \\
\hline
\end{tabular}

$\dagger$ BET (Brunauer-Emmett-Teller) surface area; $\ddagger$ mesopore diameter determined by the DFT method in the adsorption branch of the $\mathrm{N}_{2}$ isotherm at $77 \mathrm{~K}$; § specific mesopore or macropore volume obtained from the BJH cumulative specific adsorption volume of pores of 1.70 to $300.00 \mathrm{~nm}$ in diameter; || specific micropore volume calculated by subtracting $\mathrm{V}_{\text {meso }}$ from $\mathrm{V}_{t}$ (total specific pore volume determined by using the adsorption branch of the $\mathrm{N}_{2}$ isotherm at $\left.\mathrm{P} / \mathrm{P}_{\mathrm{o}}=0.95\right)$; ๆHP-MIL-53-AD (Fe) contains macropores instead of mesopores. 


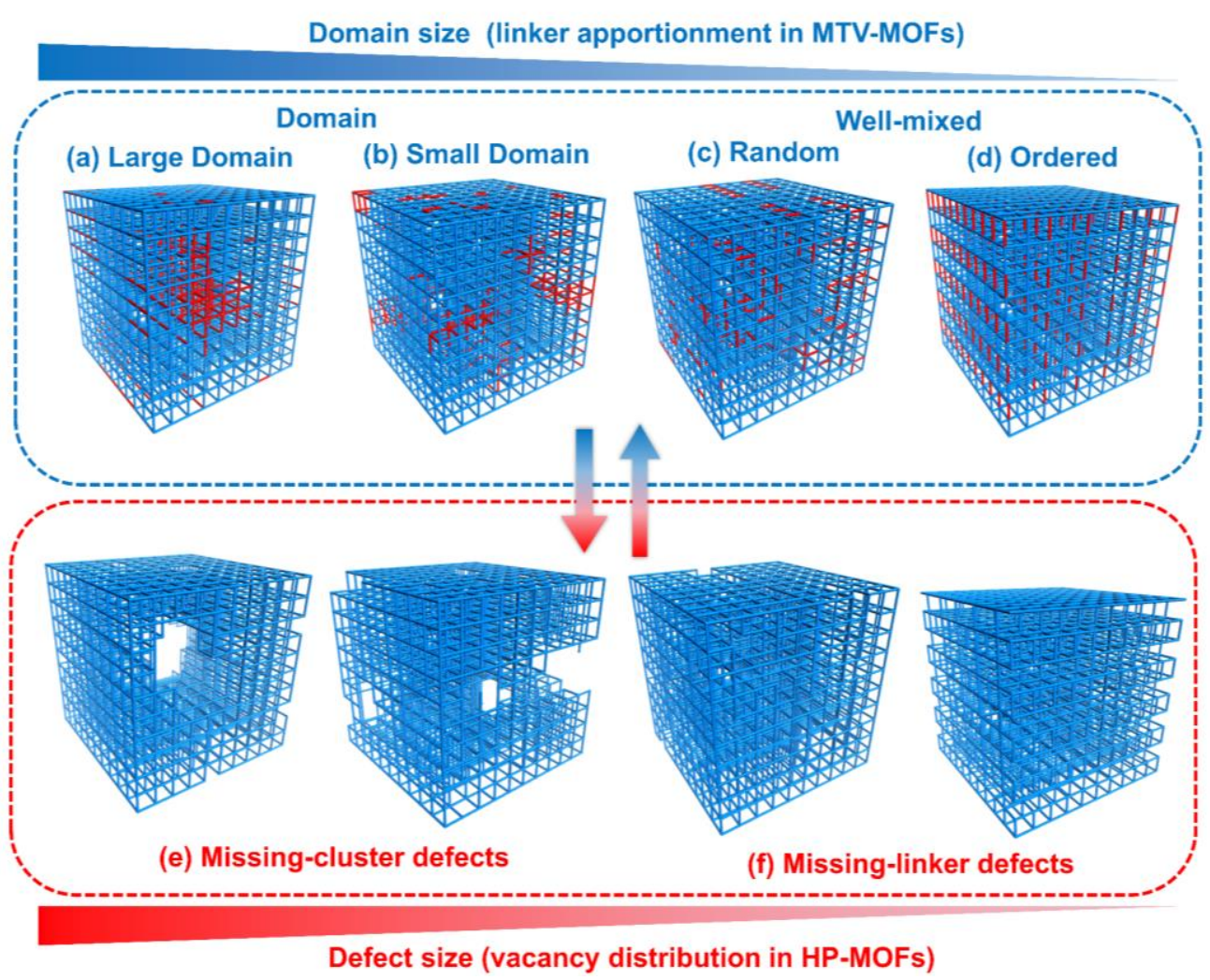

Figure 5. Relationship between linker spatial apportionment in MTV-MOFs and vacancy spatial distribution in HPMOFs. (a-d) Four scenarios of MTV-MOFs with different sizes of domain: large domain (a), small domain (b), random distribution (c), and ordered distribution (d). (e) Missing-cluster defects in HP-MOFs corresponding to domain model in MTVMOFs (a-b) after removal of labile linkers inside frameworks; (f) Missing-linker defects in HP-MOFs corresponding to wellmixed model in MTV-MOFs (c-d) after removal of labile linkers inside frameworks.

the thermolabile linkers inside frameworks. This leads to the formation of defects, whose distribution is almost identical to that of the untreated linkers. Further analysis of the defect distribution through porosity measurements and imaging techniques would enable us to deduce the original linker distribution. Conversely, by controlling the linker distribution through tuning synthetic conditions, a series of HP-MOFs with a variety of defect distributions and defect domain sizes could be constructed. From this perspective, in order to prepare HP-MOFs through linker thermolysis, the linker arrangement must follow the domain distribution models (a) and (b) (Fig. 5).

To further support the foregoing hypothesis, three typical examples of MTV-MOFs were investigated in order to show the relationship between linker distribution and vacancy apportionment. UiO-66- $\mathrm{NH}_{2}-26 \%$ prepared from one-pot synthesis exhibits a small-domain linker distribution throughout the framework. After linker thermolysis, mesopores from 2 to $20 \mathrm{~nm}$ began to arise due to the decomposition of thermolabile linkers. As indicated from TEM, the mesopores are well dispersed inside each particle. It also shows similar distribution from particle to particle. These defect apportionment information gives us a reflection about how $\mathrm{BDC}-\mathrm{NH}_{2}$ is dispersed within the matrix formed by BDC in the original MTV-UiO-66. In contrast, $\mathrm{PCN}-7 \mathrm{Oo}-\mathrm{BDC}-\mathrm{NH}_{2}$, where $\mathrm{BDC}-\mathrm{NH}_{2}$ was orderly distributed inside MOF frameworks through linker installation ${ }^{9 \mathrm{a}, 9 \mathrm{~b}}$, displays no formation of mesopores after linker thermolysis due to the ordered distribution of the thermolabile linkers (Fig. S43). This is consistent with our previous conclusion that only missing linker vacancies would not result in the formation of mesopores, while missing cluster accompanied by pore propagation would be the reason for the formation of mesopores. ${ }^{9 e}$ Another example, MTV-UiO-66-TCPP $\quad($ TCPP $=$ tetrakis (4-carboxyphenyl)porphyrin), reported by us recently ${ }^{19}$, was shown to maintain evenly mixed linker distribution as indicated from SEM-EDS mapping. After linker thermolysis, TCPP was completely removed from the framework and mesopores from 2-4 $\mathrm{nm}$ arose (Fig. S44), ruling out the possibility of domain formation inside MTV-UiO-66-TCPP. This is consistent with our previous report.

Very recently, Bueken et al. reported a similar thermal method to engineer missing-linker defects in MTV-UiO66..$^{20}$ In this case, trans-1,4-cyclohexane-dicarboxylate (cdc) was used as the thermolabile linker while BDC functioned as the thermostable linker. Presumably due to the relative flexible feature, cdc linkers tended to be well dispersed throughout the framework, as confirmed by NMR spectroscopy. After the removal of thermolabile linkers, missing-linker defects were created while no formation of mesopores was observed. This observation is consistent 
with our hypothesis here. The initial well-mixed distribution of MTV-MOF (Fig. 5c) leads to the missing-linker defects (Fig. 5f) after the removal of thermolabile linkers.

To examine whether the pristine missing-linker or -cluster defects in MTV-MOFs have essential effects on the formation of mesopores, a MTV-UiO-66-AD without modulators was synthesized under $120^{\circ} \mathrm{C}$ and the effects of the removal of thermolabile linkers were investigated (Fig. $\mathrm{S} 26)$. Compared with $\mathrm{HP}-\mathrm{UiO}-66-\mathrm{NH}_{2}-26 \%$ synthesized with acetic acid as modulators, a similar N2 sorption and pore size distribution were observed. Additionally, mesopores could also be created inside nearly defect-free $\mathrm{UiO}$ 67-GH (Fig. S37). Therefore, the formation of mesopores in MTV-MOFs should result from the domain distribution of thermolabile linkers, rather than the pristine missinglinker or -cluster defects in MTV-MOFs.

Overall, the analysis of linker distribution from vacancy apportionment in MTV-MOFs is analogous to the analysis of basic unit (amino acid/nucleotide unit) sequencing in multivariate biosystem (peptides/DNA). On one hand, the complicated assembly process from multiple linkers with various functional groups to a uniform framework is similar to that of protein or DNA from a limited number of amino acids or nucleotides, respectively. On the other hand, selective removal of the functionalized linkers from the MTV-MOFs through thermolysis is analogous to the selective removal of terminal amino acids from peptides through Edman degradation, or the selective breakage of chemically labeled sites along DNA chains through Maxam-Gilbert sequencing. The conceptual similarity among MTV-MOFs, peptides and DNA provides an inspiring solution for analyzing the unit distribution by utilizing the relationship between the integrated multivariate systems and the selectively removable individual parts.

Enhancing catalytic performance by linker thermolysis. Linker thermolysis not only affords a high level of hierarchical pores for diffusion (Fig. S45), but also creates a large number of open metal sites and ultra-small MO nanoparticles, which leads to a highly active heterogeneous MOF composite system capable of effective catalysis. Herein, we show that $\mathrm{ZrO}_{2} @ \mathrm{HP}-\mathrm{UiO}-66$ system can be used as a highly effective catalyst for Meerwein-PonndorfVerley (MPV) reaction. The MPV reaction reduces carbonyl compounds, with alcohols serving as a hydrogen donor. It can be catalyzed by a Lewis acid catalyst including $\mathrm{ZrO}_{2}, \mathrm{Zr}$-containing zeolites, and $\mathrm{Zr}$-MOFs with coordinatively-unsaturated clusters. ${ }^{21}$ The catalytic performance of resulting $\mathrm{ZrO}_{2} @ \mathrm{HP}-\mathrm{UiO}-66$ (UiO-66- $\mathrm{NH}_{2}-26 \%-350^{\circ} \mathrm{C}-2 \mathrm{~h}$ ) with $5.5 \mathrm{~nm}$ mesopores towards various ketones was evaluated. The ketones were converted to the corresponding alcohols in substantial conversion percentage via the $\mathrm{ZrO}_{2} @ \mathrm{HP}-U i \mathrm{O}-66$ composite (Fig. S47). For comparison, the catalytic activities of two reference catalysts, "defectfree" UiO-66 and $\mathrm{ZrO}_{2}$, were also examined under similar experimental conditions (Table $\mathrm{S}_{4}$ ). Compared to both of the reference catalysts, the $\mathrm{ZrO}_{2} @ \mathrm{HP}-\mathrm{UiO}-66$ composite was found to exhibit a much higher catalytic activity. This can be attributed to more exposed Lewis acidic sites on the unsaturated $\mathrm{Zr}$ clusters and ultrasmall $\mathrm{ZrO}_{2}$ nanoparticles.
Based on our experimental results and literature findings, a reaction pathway for the MPV reduction catalyzed by $\mathrm{Zr}$ based catalysts was proposed (Fig. S49). ${ }^{22}$ The exposed $\mathrm{Zr}$ coordination sites play an essential role in transferring protons from alcohols to ketones. Therefore, linker thermolysis provides a route to synthesize ultra-small nanoparticles that are catalytically active and well dispersed inside a hierarchical structure. Research along this line is now underway in our laboratory.

\section{EXPERIMENTAL SECTION}

Synthesis of UiO-66- $\mathrm{NH}_{2}-\mathrm{R} \%(\mathrm{R}=0,9,17,26,32,41$, 100). $\mathrm{ZrOCl}_{2}$ (300 mg), $\mathrm{H}_{2} \mathrm{BDC}$ (200, 180, 160, 140, 120, 100, o mg, respectively), $\mathrm{H}_{2} \mathrm{BDC}-\mathrm{NH}_{2}$ (o, 20, 40, 6o, 80, 100, 200 $\mathrm{mg}$, respectively), acetic acid (10 $\mathrm{mL}$ ) and DMF (10 $\mathrm{mL}$ ) were charged in a Pyrex vial. The mixture was heated in a $120^{\circ} \mathrm{C}$ oven for $24 \mathrm{~h}$. After cooling to room temperature, the resulted powder was separated by centrifugation and washed several times with aliquots of DMF and EtOH, respectively. The solvent was removed under vacuum at $150^{\circ} \mathrm{C}$ for $12 \mathrm{~h}$.

Synthesis of HP-UiO-66- $\mathrm{NH}_{2}-\mathrm{R} \%$-Temp-Time. Activated samples $\mathrm{UiO}-66-\mathrm{NH}_{2}-\mathrm{R} \%$ (about $120 \mathrm{mg}$ ) were placed in a thermostatic furnace. The samples were heated at a certain temperature $\left(300^{\circ} \mathrm{C}, 325^{\circ} \mathrm{C}, 35^{\circ} \mathrm{C}, 375^{\circ} \mathrm{C}, 400^{\circ} \mathrm{C}\right.$, respectively) for a certain period of time ( $15 \mathrm{~min}, 30 \mathrm{~min}$, $60 \mathrm{~min}, 120 \mathrm{~min}, 180 \mathrm{~min}, 240 \mathrm{~min}$, respectively) under air. After cooling to room temperature, the samples were activated again under vacuum at $150^{\circ} \mathrm{C}$ for $12 \mathrm{~h}$ before gas sorption experiments.

$\mathbf{N}_{2}$ sorption isotherm. Gas sorption measurements were conducted using a Micrometritics ASAP 2020 system. Prior to gas sorption measurements, about $100 \mathrm{mg}$ MOF materials UiO-66- $\mathrm{NH}_{2}-\mathrm{R} \%$ were washed thoroughly with DMF and water to remove any remaining acetic acid, and exchanged by ethanol for 3 days, during which the solvent was decanted and freshly replenished three times every day. The solvent was then removed under vacuum at $150^{\circ} \mathrm{C}$ for $12 \mathrm{~h}$, yielding porous material. After linker thermolysis, about $100 \mathrm{mg} \mathrm{UiO}-66-\mathrm{NH}_{2}-\mathrm{R} \%$-Temp-Time was treated under vacuum at $150^{\circ} \mathrm{C}$ for $8 \mathrm{~h}$ before gas sorption experiment.

In situ infrared (IR) spectroscopy. In situ IR measurements upon annealing were performed on a Nicolet 6700 FTIR spectrometer (purchased from Thermo Scientific Inc., USA) equipped with a liquid $\mathrm{N}_{2}$-cooled mercury cadmium telluride MCT-A detector. The MOFs (powder, 5 $\mathrm{mg}$ ) were gently pressed onto a $\mathrm{KBr}$ pellet $(\sim 1 \mathrm{~cm}$ diameter, 1-2 $\mathrm{mm}$ thick) and placed in the pressure cell, which is installed in the sample compartment of the infrared spectrometer with the sample at the focal point of the beam and connected to the nitrogen purge.

X-ray photoelectron spectroscopy (XPS). XPS measurements were performed with a Perkin Elmer PHI system. The sample after thermal treatment at $350^{\circ} \mathrm{C}$ for $5 \mathrm{~min}$ and $3.5 \mathrm{~h}$ respectively was transferred into the XPS chamber with a base pressure of $<1.0 \times 10-9$ Torr. Al K $\alpha(1486.6 \mathrm{eV})$ 
X-ray source at a chamber was used to excite photoelectrons. The spectra were recorded by using a 16-channel detector with a hemispherical analyzer.

Powder X-ray diffraction (PXRD). PXRD was carried out with a Bruker D8-Focus Bragg-Brentano X-ray Powder Diffractometer equipped with a $\mathrm{Cu}$ sealed tube $(\lambda=1.54178$ Å) at $40 \mathrm{kV}$ and $40 \mathrm{~mA}$.

'H NMR spectroscopy. Nuclear magnetic resonance (NMR) data were collected on a Mercury 300 spectrometer. For ${ }^{1} \mathrm{H}$ NMR spectroscopy, the activated samples (around $10 \mathrm{mg}$ ) were dissolved in $600 \mu \mathrm{L}$ DMSO- $d_{6}$ solution containing $20 \mu \mathrm{L} \mathrm{HF}$.

Thermogravimetric analysis (TGA). About $10 \mathrm{mg}$ of the sample was heated on a TGA Q50o thermogravimetric analyzer from room temperature to $600{ }^{\circ} \mathrm{C}$ at a rate of $5^{\circ} \mathrm{C} \cdot \mathrm{min}^{-1}$ under air flow of $20 \mathrm{~mL} \cdot \mathrm{min}^{-1}$. TGA-MS analyses were performed in STA449C-QMS403 C Thermal AnalysisQuadrupole Mass Spectrometer.

Transmission electron microscopy (TEM). TEM experiments were conducted on a FEI Tecnai G2 F2o ST microscope (America) operated at $200 \mathrm{kV}$.

ICP-MS analysis. Calibration standards were prepared from certified reference standards from RICCA Chemical Company. Samples were further analyzed with a Perkin Elmer NexION ${ }^{\oplus}$ 30oD ICP-MS. Resulting calibration curves have minimum $R^{2}=0.9999$. Additionally, in order to maintain accuracy, quality control samples from certified reference standards and internal standards were utilized. The individual results of the triplicate samples were averaged to determine the metal concentration.

\section{CONCLUSIONS}

In conclusion, we report a general approach, linker thermolysis, to construct ultrastable hierarchically porous structures from a series of MTV-MOFs. The thermolabile linker in the frameworks can be removed selectively through a decarboxylation process, leading to the formation of ultra-small MO@HP-MOF composites. The pore sizes can be tuned from 0.8 to $15 \mathrm{~nm}$ by controlling the temperature of thermolysis, time of heating, and ratio of thermolabile linker. The relationship between linker distribution in MTV-MOFs and vacancy apportionment in HP-MOFs was further explored. A domain linker distribution inside MTV-MOF structures plays a pivotal role to create mesopores from a microporous framework. The resulting MO@HP-MOFs exhibited enhanced adsorption properties and catalytic performances. This work not only offers a synthetic approach toward hierarchically porous structures, but also opens a door to a tunable catalytic platform for various MO@HP-MOF composites. Most importantly, linker thermolysis provides a unique tool for deciphering unit distribution in multivariate systems, mimicking biological methods by selectively removing individual parts from integrated multivariate systems.

\section{ASSOCIATED CONTENT}

Supporting Information. The Supporting Information is available free of charge on the ACS Publications website at
DOI: $10.1021 /$ jacs.xxxxxxx. Materials and methods, synthesis and characterization of HP-MOFs, mechanistic study and catalytic experiment details (PDF).

\section{AUTHOR INFORMATION}

\section{Corresponding Author}

*zhou@chem.tamu.edu

Notes

The authors declare no competing financial interest.

\section{ACKNOWLEDGMENT}

The gas adsorption-desorption studies of this research were supported as part of the Center for Gas Separations Relevant to Clean Energy Technologies, an Energy Frontier Research Center funded by the U.S. Department of Energy, Office of Science, Basic Energy Sciences under Award Number DE-SCooo1015. The PXRD, TGA-MS and TEM characterization and analysis were funded by the Robert A. Welch Foundation through a Welch Endowed Chair to HJZ (A-oozo). The spectroscopic characterization and analysis (IR and XPS) were supported by the U.S. Department of Energy, Office of Science, Office of Basic Energy Sciences under Award Number DE-FGo2-o8ER46491. The catalysis work was funded by the Qatar National Research Fund under Award Number NPRP9-377-1-o8o. The authors also acknowledge the financial supports of U.S. Department of Energy Office of Fossil Energy, National Energy Technology Laboratory (DE-FEoo26472).

\section{REFERENCES}

1. (a) Zhou, H. C.; Long, J. R.; Yaghi, O. M., Chem. Rev. 2012, 112 (2), 673-674; (b) Lee, J.; Farha, O. K.; Roberts, J.; Scheidt, K. A.; Nguyen, S. T.; Hupp, J. T., Chem. Soc. Rev. 2009, 38 (5), 14501459; (c) Li, J. R.; Kuppler, R. J.; Zhou, H. C., Chem. Soc. Rev. 2009, 38 (5), 1477-1504; (d) Li, J. R.; Sculley, J.; Zhou, H. C., Chem. Rev. 2012, 112 (2), 869-932.

2. (a) Eddaoudi, M.; Kim, J.; Rosi, N.; Vodak, D.; Wachter, J.; O'Keeffe, M.; Yaghi, O. M., Science 2002, 295 (5554), 469-472; (b) Li, M.; Li, D.; O'Keeffe, M.; Yaghi, O. M., Chem. Rev. 2014, 114 (2), 1343-1370; (c) Lu, W. G.; Wei, Z. W.; Gu, Z. Y.; Liu, T. F.; Park, J.; Park, J.; Tian, J.; Zhang, M. W.; Zhang, Q.; Gentle, T.; Bosch, M.; Zhou, H. C., Chem. Soc. Rev. 2014, 43 (16), 5561-5593; (d) Stock, N.; Biswas, S., Chem. Rev. 2012, 112 (2), 933-969; (e) Qin, J. S.; Yuan, S.; Wang, Q.; Alsalme, A.; Zhou, H. C., J. Mater. Chem. A 2017, 5 (9), 4280-4291.

3. Howarth, A. J.; Liu, Y. Y.; Li, P.; Li, Z. Y.; Wang, T. C.; Hupp, J.; Farha, O. K., Nat. Rev. Mater. 2016, 1 (3).

4. Li, P.; Modica, J. A.; Howarth, A. J.; Vargas, E. L.; Moghadam, P. Z.; Snurr, R. Q.; Mrksich, M.; Hupp, J. T.; Farha, O. K., Chem 2016, 1 (1), 154-169.

5. (a) Feng, D. W.; Gu, Z. Y.; Li, J. R.; Jiang, H. L.; Wei, Z. W.; Zhou, H. C., Angew. Chem. Int. Edit. 2012, 51 (41), 10307-10310; (b) Feng, D. W.; Liu, T. F.; Su, J.; Bosch, M.; Wei, Z. W.; Wan, W.; Yuan, D. Q.; Chen, Y. P.; Wang, X.; Wang, K. C.; Lian, X. Z.; Gu, Z. Y.; Park, J.; Zou, X. D.; Zhou, H. C., Nat. Commun. 2015, 6; (c) Mondloch, J. E.; Bury, W.; Fairen-Jimenez, D.; Kwon, S.; DeMarco, E. J.; Weston, M. H.; Sarjeant, A. A.; Nguyen, S. T.; Stair, P. C.; Snurr, R. Q.; Farha, O. K.; Hupp, J. T., J. Am. Chem. Soc. 2013, 135 (28), 10294-10297.

6. (a) Sun, L.-B.; Li, J.-R.; Park, J.; Zhou, H.-C., J. Am. Chem. Soc. 2012, 134 (1), 126-129; (b) Qiu, L.-G.; Xu, T.; Li, Z.-Q.; Wang, 
W.; Wu, Y.; Jiang, X.; Tian, X.-Y.; Zhang, L.-D., Angew. Chem. Int. Edit. 2008, 47 (49), 9487-9491; (c) Zhao, Y.; Zhang, J.; Han, B.; Song, J.; Li, J.; Wang, Q., Angew. Chem. Int. Edit. 2011, 50 (3), 636-639; (d) Cao, S.; Gody, G.; Zhao, W.; Perrier, S.; Peng, X.; Ducati, C.; Zhao, D.; Cheetham, A. K., Chem. Sci. 2013, 4 (9), 3573-3577; (e) Cai, G. R.; Jiang, H. L., Angew. Chem. Int. Edit. 2017, 56 (2), 563-567; (f) Huang, H. L.; Li, J. R.; Wang, K. K.; Han, T. T.; Tong, M. M.; Li, L. S.; Xie, Y. B.; Yang, Q. Y.; Liu, D. H.; Zhong, C. L., Nat. Commun. 2015, 6; (g) Wee, L. H.; Wiktor, C.; Turner, S.; Vanderlinden, W.; Janssens, N.; Bajpe, S. R.; Houthoofd, K.; Van Tendeloo, G.; De Feyter, S.; Kirschhock, C. E. A.; Martens, J. A., J. Am. Chem. Soc. 2012, 134 (26), 10911-10919. 7. Morris, R. E.; Cejka, J., Nat. Chem. 2015, 7 (5), 381-388. 8. (a) Wheatley, P. S.; Chlubna-Eliasova, P.; Greer, H.; Zhou, W. Z.; Seymour, V. R.; Dawson, D. M.; Ashbrook, S. E.; Pinar, A. B.; McCusker, L. B.; Opanasenko, M.; Cejka, J.; Morris, R. E., Angew. Chem. Int. Edit. 2014, 53 (48), 13210-13214; (b) Cohen, S. M., Chem. Rev. 2012, 112 (2), 970-1000; (c) Kim, Y.; Yang, T.; Yun, G.; Ghasemian, M. B.; Koo, J.; Lee, E.; Cho, S. J.; Kim, K., Angew. Chem. Int. Edit. 2015, 54 (45), 13273-13278.

9. (a) Yuan, S.; Chen, Y.-P.; Qin, J.-S.; Lu, W.; Zou, L.; Zhang, Q.; Wang, X.; Sun, X.; Zhou, H.-C., J. Am. Chem. Soc. 2016, 138 (28), 8912-8919; (b) Yuan, S.; Lu, W.; Chen, Y.-P.; Zhang, Q.; Liu, T.F.; Feng, D.; Wang, X.; Qin, J.; Zhou, H.-C., J. Am. Chem. Soc. 2015, 137 (9), 3177-3180; (c) Deria, P.; Mondloch, J. E.; Tylianakis, E.; Ghosh, P.; Bury, W.; Snurr, R. Q.; Hupp, J. T.; Farha, O. K., J. Am. Chem. Soc. 2013, 135 (45), 16801-16804; (d) Vermoortele, F.; Bueken, B.; Le Bars, G.; Van de Voorde, B.; Vandichel, M.; Houthoofd, K.; Vimont, A.; Daturi, M.; Waroquier, M.; Van Speybroeck, V.; Kirschhock, C.; De Vos, D. E., J. Am. Chem. Soc. 2013, 135 (31), 11465-11468; (e) Yuan, S. A.; Zou, L. F.; Qin, J. S.; Li, J. L.; Huang, L.; Feng, L. A.; Wang, X. A.; Bosch, M.; Alsalme, A.; Cagin, T.; Zhou, H. C., Nat. Commun. 2017, 8. 10. Guillerm, V.; Ragon, F.; Dan-Hardi, M.; Devic, T.; Vishnuvarthan, M.; Campo, B.; Vimont, A.; Clet, G.; Yang, Q.; Maurin, G.; Ferey, G.; Vittadini, A.; Gross, S.; Serre, C., Angew. Chem. Int. Edit. 2012, 51 (37), 9267-9271.

11. (a) Garibay, S. J.; Cohen, S. M., Chem. Commun. 2010, 46 (41), 7700-7702; (b) Kandiah, M.; Nilsen, M. H.; Usseglio, S.; Jakobsen, S.; Olsbye, U.; Tilset, M.; Larabi, C.; Quadrelli, E. A.; Bonino, F.; Lillerud, K. P., Chem. Mater. 2010, 22 (24), 6632-6640.

12. (a) Cavka, J. H.; Jakobsen, S.; Olsbye, U.; Guillou, N.; Lamberti, C.; Bordiga, S.; Lillerud, K. P., J. Am. Chem. Soc. 2008,
130 (42), 13850-13851; (b) Shearer, G. C.; Chavan, S.; Ethiraj, J.; Vitillo, J. G.; Svelle, S.; Olsbye, U.; Lamberti, C.; Bordiga, S.; Lillerud, K. P., Chem. Mater. 2014, 26 (14), 4068-4071; (c) Gutov, O. V.; Hevia, M. G.; Escudero-Adán, E. C.; Shafir, A., Inorg. Chem. 2015, 54 (17), 8396-8400; (d) Wu, H.; Chua, Y. S.; Krungleviciute, V.; Tyagi, M.; Chen, P.; Yildirim, T.; Zhou, W., J. Am. Chem. Soc. 2013, 135 (28), 10525-10532.

13. Cliffe, M. J.; Wan, W.; Zou, X. D.; Chater, P. A.; Kleppe, A. K.; Tucker, M. G.; Wilhelm, H.; Funnell, N. P.; Coudert, F. X.; Goodwin, A. L., Nat. Commun. 2014, 5.

14. (a) Ambrosi, M.; Fratini, E. L.; Canton, P.; Dankesreiter, S.; Baglioni, P., J. Mater. Chem. 2012, 22 (44), 23497-23505; (b) Padovini, D. S. S.; Pontes, D. S. L.; Dalmaschio, C. J.; Pontes, F. M.; Longo, E., Rsc. $A d v$. 2014, 4 (73), 38484-38490.

15. Lemaire, P. C.; Lee, D. T.; Zhao, J. J.; Parsons, G. N., Acs. Appl. Mater. Inter. 2017, 9 (26), 22042-22054.

16. Valenzano, L.; Civalleri, B.; Chavan, S.; Bordiga, S.; Nilsen, M. H.; Jakobsen, S.; Lillerud, K. P.; Lamberti, C., Chem. Mater. 2011, 23 (7), 1700-1718.

17. Gadipelli, S.; Guo, Z. X., Chem. Mater. 2014, 26 (22), $6333-$ 6338.

18. Kong, X. Q.; Deng, H. X.; Yan, F. Y.; Kim, J.; Swisher, J. A.; Smit, B.; Yaghi, O. M.; Reimer, J. A., Science 2013, 341 (6148), 882-885.

19. Sun, Y. J.; Sun, L. X.; Feng, D. W.; Zhou, H. C., Angew. Chem. Int. Edit. 2016, 55 (22), 6471-6475.

20. Bueken, B.; Van Velthoven, N.; Krajnc, A.; Smolders, S.; Taulelle, F.; Mellot-Draznieks, C.; Mali, G.; Bennett, T. D.; De Vos, D., Chem. Mater. 2017, 29 (24), 10478-10486.

21. (a) Ramanathan, A.; Villalobos, M. C. C.; Kwakernaak, C.; Telalovic, S.; Hanefeld, U., Chem. Eur. J. 2008, 14 (3), 961-972; (b) Sang, X. X.; Zhang, J. L.; Xiang, J. F.; Cui, J.; Zheng, L. R.; Zhang, J.; Wu, Z. H.; Li, Z. H.; Mo, G.; Xu, Y.; Song, J. L.; Liu, C. C.; Tan, X. N.; Luo, T.; Zhang, B. X.; Han, B. X., Nat. Comm. 2017, 8; (c) Song, J. L.; Zhou, B. W.; Zhou, H. C.; Wu, L. Q.; Meng, Q. L.; Liu, Z. M.; Han, B. X., Angew. Chem. Int. Edit. 2015, 54 (32), 9399-9403.

22. Komanoya, T.; Nakajima, K.; Kitano, M.; Hara, M., J. Phys. Chem. C 2015, 119 (47), 26540-26546. 
Table of Contents

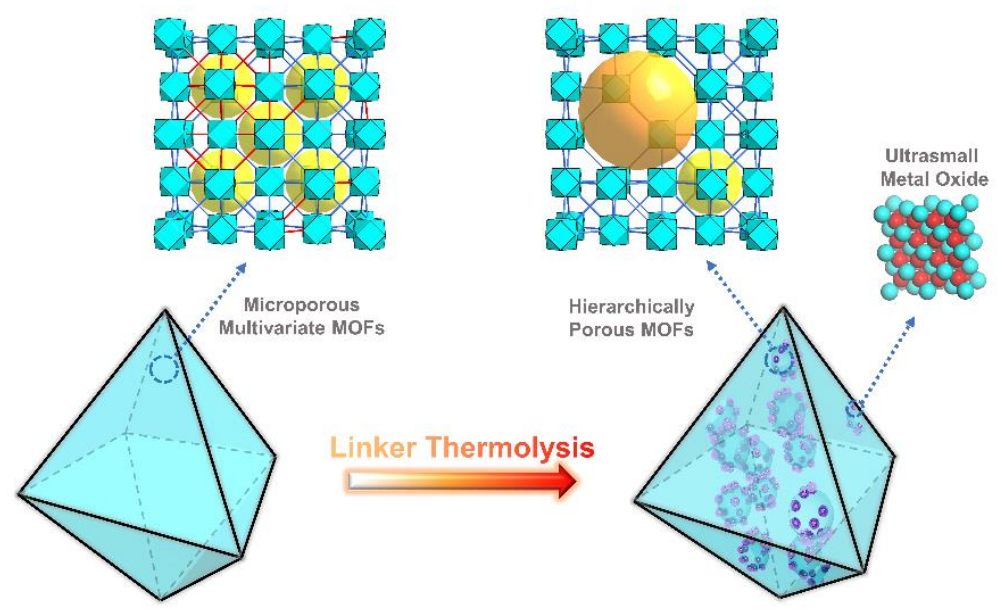

